\title{
A AUDIODESCRIÇÃO PARA FILMES PORNOGRÁFICOS
}

\author{
Felipe Vieira Monteiro ${ }^{1}$ \\ Joana Fonseca Peregrino ${ }^{2}$ \\ Virginia Maria Barcellos ${ }^{3}$
}

\begin{abstract}
RESUMO
Este artigo tem como função relatar a experiência inédita no Brasil de audiodescrição para filmes pornográficos. O projeto, que envolve 18 filmes ao todo, aconteceu entre os anos de 2020 e 2021 e teve a participação de um canal por assinatura especializado em filmes pornográficos, uma produtora de acessibilidade audiovisual e uma equipe de audiodescrição. A obra começa contextualizando o que é e como se tem desenvolvido a audiodescrição no Brasil; a seguir, busca explorar brevemente as funções de cada membro da equipe de acessibilidade para, em seguida, refletir sobre as adaptações necessárias do campo para as obras em questão, apresentando reflexões e sugestões para o gênero. O objetivo do artigo é conscientizar toda uma rede de produtores e consumidores para as necessidades e benefícios dessa ferramenta de acessibilidade audiovisual.
\end{abstract}

Palavras-chave: acessibilidade; tradução audiovisual acessível; pessoa com deficiência visual.

\begin{abstract}
This article reports the unprecedented experience in Brazil of audio description for pornographic films. The project, which involves 18 films in all, took place between the years 2020 and 2021 and had the participation of a subscription channel specialized in pornographic films, a producer of audiovisual accessibility and an audio description team. The work begins by contextualizing what audio description is and how it has developed in Brazil; then, it seeks to briefly explore the functions of each member of the accessibility team, and finally it reflects on the necessary adaptations of the field for the work in question, presenting analyses and suggestions for the genre. The objective of the article is to raise awareness of a whole network of producers and consumers about the needs and benefits of this audiovisual accessibility tool.
\end{abstract}

Keywords: accessibility; accessible audiovisual translation; visually impaired person.

\section{Introdução}

O que é a audiodescrição?

A audiodescrição é um recurso de acessibilidade comunicacional, ferramenta que propicia às pessoas com deficiência usufruir o direito à informação, à cultura e ao lazer (NAVARRO e LOPEZ, 2002). É um recurso de acessibilidade comunicacional que propicia a conversão de informações do signo visual para o signo verbal, sendo conceituada como uma tradução intersemiótica. Com o seu uso, pessoas com deficiência visual conquistam espaços profissionais exclusivos para essa comunidade, como é o caso do papel do consultor (a) que trabalha em parceira com a/o roteirista da audiodescrição (AD), profissionais que analisaremos brevemente ao longo desse texto.

\footnotetext{
${ }^{1}$ Mestrando em educação, cultura e comunicação em periferias urbanas. FEBF/UERJ.

${ }^{2}$ Mestre em Educação, gestão e difusão em Biociências UFRJ.

${ }^{3}$ ISAT-SG/ Doutoranda - Teorias do Currículo PROPED UERJ. Financiamento CAPES PROEX.
} 
Segundo Lima et al. (2009), esse recurso de tecnologia assistiva está inscrito como garantia legal (Lei Federal no 10.098/00; Decreto Federal no 5.296/04; Decreto Legislativo no 186/2008; Decreto no 6.949/2009) e se aplica aos eventos visuais, imagens estáticas ou dinâmicas, encontradas na forma de figuras, desenhos, pinturas, fotos, dentre outras, apresentadas em suportes como álbuns, catálogos, livros, slides, painéis, vídeos etc. Assim, enquanto tecnologia assistiva, a audiodescrição deve ser oferecida gratuitamente às pessoas com deficiência, uma vez que é de responsabilidade da sociedade eliminar barreiras de acessibilidade - o que efetivamente se alcança com esse recurso, posto que preenche lacunas informacionais, também no que tange aos eventos visuais (LIMA, 2010).

Se antes pensava-se que era a deficiência que causava a incapacidade na pessoa, hoje nos é claro que são as barreiras sociais (barreiras atitudinais) que, de fato, limitam e impedem as pessoas com deficiência no exercício pleno dos seus direitos. A Convenção sobre os Direitos da Pessoa com Deficiência considera que o conceito de deficiência é um conceito em evolução e

resulta da interação entre pessoas com deficiência e as barreiras devidas às atitudes e ao ambiente que impedem a plena e efetiva participação dessas pessoas na sociedade em igualdade de oportunidades com as demais pessoas. (DECRETO 6949/2009)

Entendendo que as barreiras atitudinais estão presentes na sociedade e, portanto, permeiam a falta de acessibilidade comunicacional, o acesso à audiodescrição vem, neste contexto, interromper a inércia de dois aspectos importantes: a crença de que as pessoas com deficiência visual são incapazes de apreciar o mundo das imagens, ou que não têm interesse em fazê-lo; e a crença de que se deve oferecer acessibilidade comunicacional apenas por imposição legal.

Quando a audiodescrição é ofertada de acordo com os preceitos inclusivos, quebra não só barreiras comunicacionais, mas também atitudinais. Para que isso possa ocorrer, contudo, a oferta da audiodescrição deve levar em consideração as diretrizes da tradução visual; a ética profissional do tradutor visual, bem como os preceitos inclusivos. Nesse sentido, o audiodescritor deve, por exemplo, evitar práticas paternalistas, condescendentes, que subestimem e inferiorizem o público final da audiodescrição, ou, ainda, que compactuem com generalizações, estereótipos ou tabus a respeito das pessoas com deficiência.

Lima et al. (2010), ao tratarem das barreiras atitudinais na audiodescrição, definem: Barreira Atitudinal de Generalização; Barreira Atitudinal de Padronização; Barreira Atitudinal de Piedade; Barreira Atitudinal de Estereótipos; Barreira Atitudinal de Compensação. Não 
vamos nos aprofundar em cada uma, porém sugerimos a leitura do artigo citado. Nem tudo que é visto será possível descrever, portanto, não se deve procurar compensar o espectador com deficiência com informações que ainda não estão disponíveis aos demais. A audiodescrição visa à igualdade de acesso aos conteúdos, e antecipar ou interpretar, além de desigualar os espectadores, subestima a capacidade de entendimento do espectador com deficiência (LIMA et al., 2010).

A cegueira não determina a pessoa, mas certamente influencia o modo como ela vê as coisas ao seu redor, como ela recepciona a informação visual traduzida em palavras - o que obriga o audiodescritor a considerar "a cegueira e a baixa visão" em suas escolhas tradutórias (SNYDER, 2011). Sendo assim, em vez de estabelecer "regras" de como as audiodescrições devem ser feitas, estudar o modo como elas são realizadas parece-nos mais relevante para a provisão de uma tradução visual com qualidade, que corresponda a diretrizes técnicas, de escolha intelectual do tradutor e que considere os clientes do serviço.

A tradução visual, aqui na forma de audiodescrição, pode ser considerada tecnologia assistiva, visto que consiste em uma atividade que proporciona uma nova experiência com as imagens, em lugar da experiência visual perdida. É tecnologia assistiva porque permite acesso aos eventos imagéticos em que a experiência visual jamais foi experimentada. E, em ambos os casos, é recurso inclusivo, à medida que permite participação social das pessoas com deficiência, com igualdade de oportunidade e condições com seus pares videntes.

A produção de uma audiodescrição é ditada pela consideração da obra e do usuário a que ela se destina, sendo que é esse conjunto que exige do tradutor e do consultor o que traduzir, como traduzir, quando e quanto traduzir. Em toda tradução é necessário que o tradutor faça constantemente edições e escolhas. Assim, lhe são exigidos a pesquisa, a leitura e o desenvolvimento de espírito crítico, para que possa executar, de maneira eficaz e com responsabilidade, as edições e as escolhas tradutórias.

A audiodescrição, enquanto gênero tradutório, não foge à regra, devendo o tradutor que pretende assumir tal ofício ser um pesquisador por excelência: um estudioso das imagens e das palavras que as traduzem, sendo as primeiras a "língua-fonte", a segunda, a de chegada.

Nas palavras de Vieira e Lima (2010):

[...] Todo trabalho de tradução exige disciplina mental, paciência, raciocínio e sensibilidade para se compreender como o outro compreende. Isto não é diferente no caso da audiodescrição, pois ela requer uma exegese da audiência, no sentido da 
compreensão de como as audiências receptoras reagirão às diferentes possibilidades de construção dos discursos descritivos.

Estamos cientes das diferentes possibilidades de construção dos discursos descritivos, assim como das diferentes possibilidades de entendimento. Uma audiodescrição não pode ser criada sem um cauteloso planejamento do que é necessário ser veiculado, do que vai, do que não vai, e como vai ser dito. Um trabalho de alta seletividade, principalmente sabendo que será necessário lidar com frequentes restrições de tempo, no caso das exibições de imagens dinâmicas, ou restrições de espaço, no caso das imagens estáticas. Assim sendo, nenhuma outra pessoa será melhor em preencher tais requisitos técnicos e científicos que não os profissionais treinados e habilitados: o audiodescritor e o consultor.

O diferencial entre o tradutor de língua e o tradutor de eventos visuais (audiodescritor e consultor) porém, está em que a este último não basta verter de A para B. Ele deve traduzir as imagens em palavras tendo em mente o empoderamento do usuário e, do ponto de vista da técnica audiodescritiva, a narração dessa tradução - seja ela feita por meio de um narrador/audiodescritor (em um teatro, por exemplo); por um narrador (em um audioguia, no museu ou no parque); por um sintetizador de voz (lendo uma página web ou o arquivo de um livro, no computador), seja, ainda, por um usuário com deficiência visual (pessoa cega ou surdocega, por exemplo), que esteja lendo em uma linha Braille em um livro, em um catálogo ou em qualquer outro suporte Braille.

O produto final da tradução do audiodescritor pode, então, aparecer na forma de uma locução, na impressão Braille da descrição ou em um roteiro audiodescritivo. Quanto a esse último, Tavares et al. (2010) lembram que a produção do roteiro audiodescritivo, isto é, a tradução visual registrada tecnicamente no suporte físico, nem sempre vai ser oralizada (locucionada) pelo tradutor visual que a produziu, o que requer cuidados próprios ao ofício de audiodescrever. Independente de a imagem ser estática ou dinâmica, a apropriação do contexto é fundamental para a qualidade da audiodescrição, seja ela efetivada ao vivo, como no caso de teatro e dança; gravada, como em filmes; seja ainda escrita, acompanhando imagens estáticas, registradas em suportes textuais diversos: livros, folders, blogs etc. Nesse estudo prévio, o audiodescritor fundamenta a elaboração do roteiro, comumente utilizado quando o material artístico, cultural, publicitário é dinâmico.

O roteiro é um recurso de suporte para a execução do trabalho do audiodescritor que deverá ser discutido com um consultor, além de artistas ou pessoas envolvidas na atividade em questão, quando possível. Assim, quanto mais o roteiro é debatido, analisado e revisado, 
mais susceptível a acertos. Como já indicado acima, quem faz o roteiro não será necessariamente quem realizará a narração, portanto, é essencial que o texto seja claro e fiel ao objeto da audiodescrição. Sugere-se que os tempos e intenções da narração sejam previstos mediante a inclusão de rubrica (Tavares et al., 2010). Tal sugestão faz-se necessária para auxiliar o audiodescritor na narração de seu roteiro. A rubrica é necessária não só na produção do roteiro para locução de espetáculos e filmes, mas também para a audiodescrição de imagens estáticas (fotografias, pinturas, esculturas etc.), presentes em museus, em igrejas, ou em outros ambientes, independentemente do suporte em que aparecerem.

De fato, conforme Lima et al. (2009), a audiodescrição não é a mera somatória dos termos áudio e descrição, mas a construção de um novo conceito a partir da união da descrição e do que, sendo descrito, é oralizado por voz humana ou sintetizada. Portanto, tensionados na audiodescrição estão a obra, os usuários, as diretrizes tradutórias da tradução visual, o conhecimento a respeito do que se tem chamado de "visualidade" e, não menos importante, as regras da transcrição oral, uma vez que serão necessários roteiros audiodescritivos a serem lidos por audiodescritores ou por narradores diversos.

\section{A consultoria em audiodescrição}

O envolvimento direto da pessoa com deficiência visual na produção da audiodescrição, pelo fato de ser o público-alvo do recurso, é muito importante. No entanto, não basta ser uma pessoa com deficiência para tornar-se consultor em audiodescrição. Sá (2015) afirma que a formação de audiodescritores potencializa a articulação entre a teoria e a prática da audiodescrição aplicada a todas as áreas de conhecimento. A consultora (2015) afirma que a amplitude e a abrangência da formação em audiodescrição contribui para o desenvolvimento de múltiplas habilidades e para transferência de aprendizagem. Conclui que, neste processo, os consultores são sujeitos da formação em audiodescrição tanto quanto os audiodescritores roteiristas e narradores.

$\mathrm{Na}$ construção do perfil do consultor em audiodescrição, além da formação, outros aspectos são relevantes. Segundo Monteiro (2018), as pessoas com deficiência visual, enquanto consumidoras, são as maiores autoridades para dizer se um produto ou um trabalho está de acordo com suas necessidades. Para isso, Monteiro e Perdigão (2020) afirmam que o profissional deve possuir uma boa circulação em equipamentos culturais tais como museus, 
teatros, galerias de arte, cinemas, entre outros, com recursos de acessibilidade prioritariamente.

A produção de um roteiro de audiodescrição é feita o partir da parceria entre roteirista e consultor. Essa relação deve ser saudável para que ambos possam sugerir e inferir sobre as melhores escolhas tradutórias para um texto conciso, inteligível, coeso e vívido. Ao receber o roteiro parcial, o consultor deve revisar sentença por sentença com a finalidade de entender se as descrições colaboram de maneira efetiva para a formação imagética. Por fim, o consultor deve ter em mente que, ao prestar consultoria em audiodescrição, está representando uma comunidade de pessoas com deficiência visual heterogênea. Assim, o profissional não pode basear-se somente em suas convicções pessoais, sendo necessário pensar no coletivo.

\section{A audiodescrição para o audiovisual no mundo e no Brasil}

Nossa sociedade carrega um histórico de segregação, exclusão, infantilização e apagamento das pessoas com deficiência. Fato este que começa a se modificar a partir da revolução industrial, quando este público começa a ser visto como potencial produtivo. A partir disso, novas demandas foram surgindo, como a criação de instituições especializadas para atender as especificidades dessas pessoas. Recurso de uso recente no Brasil, a audiodescrição vem ganhando campo de modo diversificado através de leis e conscientização da população para a importância da ferramenta a um grande percentual da população.

Nesse contexto, é importante citar que a audiodescrição existe há pouco mais de 40 anos, segundo Franco e Silva (2010). De acordo com as autoras, em meados dos anos 1970 ela surge, nos Estados Unidos, a partir da idealização de Gregory Frazier, documentada em sua dissertação de mestrado no ano de 1975. Margaret Rockwel (pessoa com deficiência visual), fundadora do serviço de ledores via rádio The Metropolitan Washington Ear, e Cody Pfanstiehl (ledor voluntário do projeto), em 1981, foram responsáveis pela audiodescrição de Major Barbara, peça exibida no Arena Stage Theater em Washington DC, e a partir disso as portas abrem-se para a audiodescrição se espalhar pelo mundo.

Sobre a marginalização das pessoas com deficiência, é fato que ainda precisamos avançar. Todavia, conquistas relevantes, no que tange à legislação, tanto nacional quanto internacional, vêm marcando a história das pessoas com deficiência - tais como as convenções, tratados, declarações, leis, decretos e portarias que garantem os direitos desse segmento da sociedade. 
Nesse contexto de legislação, podemos destacar a lei brasileira de inclusão/estatuto da pessoa com deficiência de $\mathrm{n}^{\mathrm{o}} 13.146$ de 6 de julho de 2015, que traz apontamentos importantes já em seu Art. $1^{\text {o }}$ :

É instituída a Lei Brasileira de Inclusão da Pessoa com Deficiência (Estatuto da Pessoa com Deficiência), destinada a assegurar e a promover, em condições de igualdade, o exercício dos direitos e das liberdades fundamentais por pessoa com deficiência, visando à sua inclusão social e cidadania. (BRASIL, 2015)

A partir desse artigo, se estabelece a garantia de as pessoas com deficiência estarem em igualdade com as demais da sociedade. Além disso, essa lei cita claramente o acesso igualitário aos produtos audiovisuais no Art. $67^{\circ}$ :

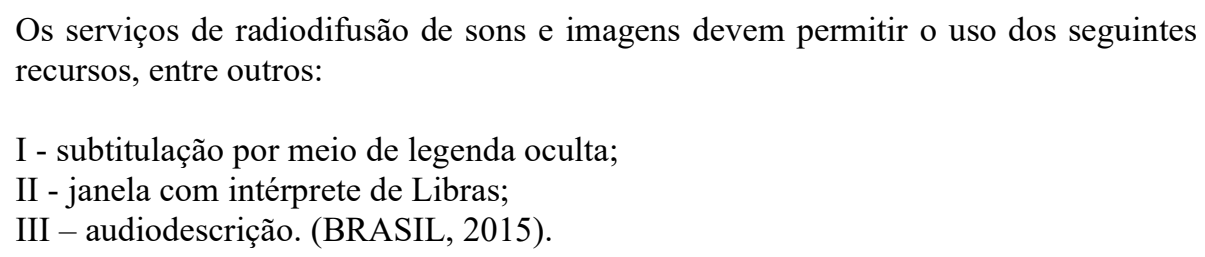

Dado o exposto, a lei é clara no que tange ao acesso audiovisual por meio da audiodescrição.

No Brasil, a entrada formal do recurso acontece no ano de 2003 por conta do Festival Internacional Assim Vivemos (http://www.assimvivemos.com.br/2019/), que já conta com nove versões. O festival exibe filmes que abordam as superações vividas por pessoas com deficiência e seu processo de empoderamento nas atividades diárias. O evento acontece de dois em dois anos.

Segundo Motta (2004), na televisão, a audiodescrição começou a ser implementada em julho de 2011, depois de grandes embates entre pessoas com deficiência visual e audiodescritores de um lado, radiodifusores e Ministério das Comunicações de outro. De duas horas diárias, como era previsto por lei para ser implementado em 2008, chegando a $100 \%$ da programação televisiva em 10 anos, a carga horária de programação audiodescrita foi drasticamente reduzida para insignificantes 2 horas semanais a partir de julho de 2011 e ampliada para 4 horas semanais em julho de 2013. No momento, o recurso está disponível em alguns programas nos canais digitais de emissoras com sinal aberto, em um segundo canal de áudio. 


\section{Cenário dos filmes pornográficos acessíveis no Brasil}

Segundo dados de pesquisa realizada em 2018 pela empresa Quantas Pesquisas e Estudos de Mercado, há no Brasil 22 milhões de pessoas que assumem consumir pornografia. Desse público, $76 \%$ são homens e $24 \%$ são mulheres. A maior parte é jovem ( $58 \%$ têm menos de 35 anos), de classe média alta (49\% pertencem à classe B) e está em um relacionamento sério (69\% são casados ou estão namorando). Além disso, 49\% do público concluíram o ensino médio e 40\% têm curso superior (MURARO, 2018).

A TV por assinatura brasileira oferta alguns canais de conteúdo erótico e pornográfico, nacionais e estrangeiros. São eles:

Sexy Hot: fundado em 1996, pertence ao grupo Playboy do Brasil Entretenimento é o "maior e mais importante do segmento" (SEXY HOT, 2021). A programação é composta por filmes nacionais e heterossexuais, além de filmes exclusivos e próprios do canal, feitos através do selo Sexy Hot Produções. O público feminino representa 54\% de seus assinantes.

Playboy TV: em operação desde 1996, é versão para a América Latina do tradicional canal americano e conta, segundo informações do site, com conteúdo explícito, sensual e heterossexual. Sua programação é $100 \%$ internacional, composta por reality shows, programas, filmes e novelas.

Venus: fundado em 1995, o primeiro canal adulto da América Latina é destinado "a quem busca um canal erótico sem tabus, que ultrapasse os limites convencionais".

Sextreme: fundado em 2011, segundo a apresentação do canal disponível na internet, "é o canal mais ousado do mundo adulto. Seu conteúdo é perfeito para quem gosta de orgia, sadomasoquismo e dominação. Com uma programação heterossexual, (...) inspira a inovar na cama, apimentando o sexo. Aqui as suas fantasias mais secretas vão se realizar" (SEXTREME, 2021).

SexPrivé: fundado em 2009, é o canal de conteúdo adulto criado pelo Grupo Bandeirantes. É o primeiro canal a oferecer aos assinantes programação adulta exclusivamente brasileira.

\section{O processo}

Ainda inédito no Brasil, o campo dos filmes pornográficos ainda não havia sido problematizado no país. Sendo assim, este artigo tem como função relatar a experiência inédita no Brasil de audiodescrição para filmes pornográficos. Gostaríamos de sinalizar que o 
projeto de acessibilidade para os conteúdos do canal Sexy Hot também incluiu a produção de legendas descritivas, que eram entregues finalizadas nos filmes, no entanto, esse processo não será objeto deste artigo.

O projeto, que envolve 18 filmes ao todo, aconteceu entre março de 2020 e agosto de 2021, envolvendo o selo Sexy Hot, e uma equipe de audiodescrição. A equipe, montada especialmente para o projeto, relata e reflete nas próximas linhas sobre as descobertas e desafios ao desenvolver os produtos.

O projeto (audiodescrição para filmes de conteúdo adulto) surgiu a partir de uma conversa entre a diretora da Conecta Acessibilidade e a diretora do Canal Sexy Hot, Cinthia Fajardo, primeira mulher à frente de um canal pornográfico no país. Em reunião, foram colocados os números de pessoas com deficiência visual e auditiva no Brasil e a inexistência de acessibilidade audiovisual para conteúdos pornográficos no país. Ao mesmo tempo, o canal já estava focando em diversidade na sua produção. Fajardo (2021) destaca sua preocupação com os novos desafios quando assume a direção do canal:

Estamos investindo em melhorias contínuas e em mudanças na nossa plataforma de streaming, esse é o nosso foco. O sexyhot.com.br está de cara nova e com uma experiência mais completa para os assinantes. A mudança, que já está no ar, chega para facilitar a busca por conteúdos e aprimorar a navegabilidade. Além disso, queremos que o nosso conteúdo abrace o maior número de consumidores possíveis, onde todos consigam se sentir representados. Vamos adaptar os filmes do Sexy Hot Produções esse ano para deficientes visuais e auditivos, disponibilizamos conteúdos trans no site, e queremos fazer com que o elenco e as histórias estejam cada vez mais diversas. (SACCHITIELLO, 2020)

A partir da real possibilidade de produção de acessibilidade para conteúdos pornográficos, a produtora Conecta Acessibilidade pesquisou, na web, sites de filmes pornôs com audiodescrição. Destacou-se, para a reunião com o canal, os conteúdos de dois sites americanos que ofertavam audiodescrição em seus conteúdos: PornHub e Porn for the Blind.

Com o início oficial do projeto junto ao Canal Sexy Hot, a Conecta Acessibilidade passou a buscar profissionais de audiodescrição e de legendas descritivas que aceitassem fazer parte do projeto. Alguns profissionais consultados não se sentiram à vontade para realizar a tradução e alegaram desconforto com o conteúdo. Importante mencionar que os profissionais que hoje realizam esse trabalho de tradução para a Conecta Acessibilidade nunca tinham feito antes tradução de conteúdos pornográficos, no entanto, o gênero fílmico não os incomodou, foi considerado mais um desafio e uma oportunidade, visto o ineditismo do projeto. 
Fechada a equipe e feitas as pesquisas individuais, foi realizada uma reunião presencial entre a roteirista e narradora, a tradutora e legendadora, o consultor cego, a assistente de produção do projeto e a produtora da acessibilidade. Nessa reunião, refletiram acerca de dúvidas, inquietações e entusiasmos, além de estabelecer as diretrizes iniciais para a produção dos primeiros filmes.

Antes de entregar o primeiro filme acessível ao canal, intitulado Sugar Daddy, foi encaminhada uma pesquisa a sete pessoas cegas e consumidoras de conteúdo pornô. Junto à pesquisa foi encaminhada a audiodescrição do filme, mixada ao som original, para análise do conteúdo e respostas ao questionário com 10 perguntas. A pesquisa foi criada de modo a ajustar detalhes da produção como, por exemplo, velocidade e tom de voz da narradora, vocabulário e satisfação com a audiodescrição, dentre outras perguntas, e, assim, validar a acessibilidade junto ao seu público final. Importante mencionar que o canal autorizou à produtora da acessibilidade o envio da audiodescrição aos respondentes.

As perguntas realizadas foram:

1. Você gostou da voz da narração? Responda Sim ou Não e se quiser justifique a sua resposta.

2. Você gostou do tom da voz? Responda Sim ou Não e se quiser justifique a sua resposta.

3.Você gostou da velocidade da narração? Responda Sim ou Não e se quiser justifique a sua resposta.

4.Você compreendeu o enredo do filme? Responda Sim ou Não e se quiser justifique a sua resposta.

5.Você gostou do volume da audiodescrição? Responda Sim ou Não e se quiser justifique a sua resposta.

6.Você tem interesse em assistir outros filmes deste canal com o recurso da audiodescrição? Responda Sim ou Não e se quiser justifique a sua resposta.

7. Com que frequência você assiste a conteúdo pornô?

8. SEU GÊNERO: (não obrigatório)

9. ORIENTAÇÃO SEXUAL: (não obrigatório)

10. Você gostaria de deixar alguma sugestão ou fazer algum comentário?

Foram consultados 7 mulheres e homens cegos que consomem o gênero pornográfico com constância.

As respostas estão dispostas no quadro a seguir: 
Quadro 1 - Avaliação da audiodescrição por consumidores

\begin{tabular}{|c|c|c|c|c|c|c|c|}
\hline & \multicolumn{7}{|c|}{ ENTREVISTADOS } \\
\hline PERGUNTAS & Entrevistado 1 & Entrevistado 2 & Entrevistado 3 & Entrevistado 4 & Entrevistado 5 & Entrevistado 6 & Entrevistado 7 \\
\hline $\begin{array}{l}\text { 1. Você gostou } \\
\text { da voz da } \\
\text { narração? } \\
\text { Responda Sim ou } \\
\text { Não e se quiser } \\
\text { justifique a sua } \\
\text { resposta. }\end{array}$ & Sim & $\begin{array}{l}\text { Sim, uma voz } \\
\text { bem } \\
\text { imparcial, e } \\
\text { que não } \\
\text { atrapalhou a } \\
\text { dinâmica do } \\
\text { filme. }\end{array}$ & Sim & $\begin{array}{l}\text { Sim, uma voz } \\
\text { bem } \\
\text { imparcial, e } \\
\text { que não } \\
\text { atrapalhou a } \\
\text { dinâmica do } \\
\text { filme. }\end{array}$ & Sim & \begin{tabular}{|c|} 
Sim, só penso \\
que poderia \\
expressar um \\
pouco mais do \\
clima/emoção \\
do filme.
\end{tabular} & Sim \\
\hline $\begin{array}{l}\text { 2. Você gostou } \\
\text { do tom da voz? } \\
\text { Responda Sim ou } \\
\text { Não e se quiser } \\
\text { justifique a sua } \\
\text { resposta. }\end{array}$ & $\begin{array}{c}\text { Não. Um } \\
\text { pouco } \\
\text { automático. }\end{array}$ & Sim & Sim & Sim & Sim & $\begin{array}{c}\text { Sim, excelente } \\
\text { tom de voz. } \\
\text { Uma "pitada" } \\
\text { de emoção e } \\
\text { ficaria melhor } \\
\text { ainda. }\end{array}$ & $\begin{array}{l}\text { O tom poderia ser } \\
\text { alternado ao longo } \\
\text { do filme, para mais } \\
\text { suave. O tom na } \\
\text { descrição dos } \\
\text { personagens, do } \\
\text { ambiente, cenas } \\
\text { externas poderia } \\
\text { se diferenciar } \\
\text { quando no calor do } \\
\text { clima erótico. A } \\
\text { entonação dos } \\
\text { pontos finais a } \\
\text { cada frase, } \\
\text { poderiam ser } \\
\text { melhor } \\
\text { vocalizadas, pois } \\
\text { há muitas } \\
\text { passagens de } \\
\text { locução onde } \\
\text { caberia mais uma } \\
\text { suspensão, tal } \\
\text { como um ponto e } \\
\text { vírgula }\end{array}$ \\
\hline $\begin{array}{l}\text { 3.Você gostou da } \\
\text { velocidade da } \\
\text { narração? } \\
\text { Responda Sim ou } \\
\text { Não e se quiser } \\
\text { justifique a sua } \\
\text { resposta. }\end{array}$ & $\begin{array}{c}\text { Não. Um } \\
\text { pouco } \\
\text { automático. }\end{array}$ & $\begin{array}{c}\text { Não, } \\
\text { introdução } \\
\text { rápida, não } \\
\text { dando para } \\
\text { imaginar a } \\
\text { cena }\end{array}$ & Sim & $\begin{array}{l}\text { Sim, ficou } \\
\text { bom pra } \\
\text { entender }\end{array}$ & Sim & \begin{tabular}{|} 
Sim. No início \\
achei bem \\
corrido, mas \\
imagino que \\
pela \\
velocidade das \\
informações. \\
Não sei se \\
daria para \\
diminuir um \\
pouco a \\
velocidade.
\end{tabular} & $\begin{array}{l}\text { Não, por vezes } \\
\text { muito rápido } \\
\text { demais, o que } \\
\text { quebra o clima. }\end{array}$ \\
\hline $\begin{array}{l}\text { 4.Você } \\
\text { compreendeu o } \\
\text { enredo do filme? } \\
\text { Responda Sim ou } \\
\text { Não e se quiser } \\
\text { justifique a sua } \\
\text { resposta. }\end{array}$ & Sim & $\begin{array}{c}\text { Não, na hora } \\
\text { da escada e } \\
\text { corrimão não } \\
\text { dá p saber se } \\
\text { foi penetração } \\
\text { vaginal ou } \\
\text { anal }\end{array}$ & Sim. & Sim & Sim & \begin{tabular}{|c|} 
Sim. O \\
entendimento \\
do enredo é \\
tranquilo e com \\
a \\
audiodescriçã \\
o a \\
experiência \\
fica ainda \\
melhor! \\
\end{tabular} & Sim \\
\hline $\begin{array}{l}\text { 5.Você gostou do } \\
\text { volume da } \\
\text { audiodescrição? } \\
\text { Responda Sim ou } \\
\text { Não e se quiser } \\
\text { justifique a sua } \\
\text { resposta. }\end{array}$ & Sim & Sim & $\begin{array}{c}\text { Não } \\
\text { respondeu }\end{array}$ & Sim & Sim & $\begin{array}{l}\text { Sim. O volume } \\
\text { ficou ótimo. }\end{array}$ & Sim \\
\hline
\end{tabular}




\begin{tabular}{|c|c|c|c|c|c|c|c|}
\hline & \multicolumn{7}{|c|}{ ENTREVISTADOS } \\
\hline PERGUNTAS & Entrevistado 1 & Entrevistado 2 & Entrevistado 3 & 3 Entrevistado 4 & Entrevistado 5 & Entrevistado 6 & Entrevistado 7 \\
\hline $\begin{array}{l}\text { 6.Você tem } \\
\text { interesse em } \\
\text { assistir outros } \\
\text { filmes deste canal } \\
\text { com o recurso da } \\
\text { audiodescrição? } \\
\text { Responda Sim ou } \\
\text { Não e se quiser } \\
\text { justifique a sua } \\
\text { resposta. }\end{array}$ & Sim & Sim & $\begin{array}{c}\text { Sim, } \\
\text { precisamos } \\
\text { conquistar } \\
\text { mais } \\
\text { espaços } \\
\text { acessiveis }\end{array}$ & Sim & \begin{tabular}{|} 
Sim, pela \\
importância \\
da \\
acessibilidad \\
e
\end{tabular} & $\begin{array}{c}\text { Sim. O } \\
\text { mercado não } \\
\text { oferece quase } \\
\text { nenhuma } \\
\text { opção para a } \\
\text { demanda } \\
\text { desse público. }\end{array}$ & Sim \\
\hline $\begin{array}{l}\text { 7. Com que } \\
\text { frequência você } \\
\text { assiste a } \\
\text { conteúdo pornô. }\end{array}$ & Mais de $5 \mathrm{x} / \mathrm{mês}$ & 2-5 x/mês & 2-5 x/mês & $1 \mathrm{x} /$ mês & 2-5 x/mês & $\begin{array}{c}2-5 \text { vezes ao } \\
\text { mês }\end{array}$ & 1 vez ao mês \\
\hline \begin{tabular}{|l} 
8. SEU \\
GÊNERO:(não \\
obrigatório)
\end{tabular} & masculinno & feminino & feminino & masculino & não binário & feminino) & feminino \\
\hline $\begin{array}{l}\text { 9. ORIENTAÇÃO } \\
\text { SEXUAL: (não } \\
\text { obrigatório) }\end{array}$ & homossexual & heterossexual & bissexual & heterossexual & pansexual & heterossexual & heterosexual \\
\hline $\begin{array}{l}\text { 10.Você gostaria } \\
\text { de deixar alguma } \\
\text { sugestão ou } \\
\text { fazer algum } \\
\text { comentário? }\end{array}$ & Nâo & \begin{tabular}{|} 
Introdução \\
muito rápida, \\
qdo fala q o \\
homem \\
coloca a boca \\
na buscará, \\
abre w fecha, \\
confuso, \\
Cleber atende \\
o telefone no \\
bar, se joga \\
no sofá, o \\
sofá era no \\
bar?? Na \\
escala, \\
quando \\
Soraya \\
encaixe, é \\
anal ou nao??
\end{tabular} & $\begin{array}{l}\text { Não } \\
\text { respondeu }\end{array}$ & $\begin{array}{c}\text { Não } \\
\text { respondeu }\end{array}$ & $\begin{array}{l}\text { Não } \\
\text { respondeu }\end{array}$ & $\begin{array}{l}\text { Não } \\
\text { respondeu }\end{array}$ & Não respondeu \\
\hline
\end{tabular}

Fonte: Conecta Acessibilidade (2020)

As respostas foram positivas para a grande maioria dos questionamentos elencados pela produtora da acessibilidade, pela roteirista e narradora da audiodescrição e pelo consultor cego do projeto. Assim, considerou-se que o primeiro roteiro e a narração de audiodescrição para o filme brasileiro Sugar Daddy estavam aprovados e o produto pronto para ser entregue e exibido pelo canal. 


\section{A audiodescrição para o audiovisual pornográfico}

Embora existam normas bastante difundidas e praticadas para a elaboração de roteiros e narrações de audiodescrição, quando entramos no universo erótico, outros desafios são somados. Cremos que um dos maiores é como harmonizar as normas com o imaginário que os consumidores do produto buscam, ou seja: como ser ético sem cortar o tesão de quem assiste. Consumidor dos canais de contos eróticos na internet, entre outros produtos similares, a pessoa que procura a audiodescrição em filmes de conteúdo adulto pode, em um primeiro momento, estranhar o tom distanciado na narradora. Mesmo sendo aprovada nas pesquisas iniciais, a equipe buscava, a cada filme, novas possibilidades de entonação, temperatura, ritmo e velocidade que soassem mais orgânica a proposta do filme.

Por outro lado, por serem filmes com poucos diálogos e com som geralmente inferior às obras comerciais difundidas nos cinemas e canais de streaming, a pessoa que constrói o roteiro tem mais tempo e calma para explorar e descrever o que está na tela. Essa riqueza de detalhes antes inexistente, podendo ser narrada ao longo da obra respeitando ritmos e intervalos, proporciona ao consumidor final uma experiência nunca antes possível.

Outro ponto que se nota é a forma como esses produtos são consumidos. Diferente das obras em que prevalece uma dramaturgia, esses filmes podem ser vistos de maneira linear ou não, com objetivos para além de se apreciar a trama. Tentamos respeitar essa característica ao preservar o som original sem interrupções das cenas de sexo em que uma ascensão é notada. Ainda dentro do mesmo espectro, foram necessárias pesquisas e leituras com pessoas de diferentes partes do país para que fosse possível a criação de um vocabulário popular - e ao mesmo tempo sem regionalismos. Por ser um canal de abrangência nacional, esses pontos foram bastante trabalhados.

Mesmo sendo um canal de filmes heterossexuais, talvez pelo ineditismo do trabalho, percebemos que a comunidade cega homoafetiva também demostrou interesse pelos filmes. Com isso, surgem demandas diferentes, mas não menos interessantes e justas. Começamos a perceber que a descrição feita da mulher era sempre mais detalhada que a do homem. A única hipótese que pode explicar esse fato, até agora, é que o tempo de câmera no corpo feminino é infinitamente maior que no masculino. Além disso, começamos a nos questionar sobre a carga de significado que palavras como "consolo" poderiam trazer ao roteiro. Ainda que não caiba ao roteirista expressar seu julgamento durante a confecção, talvez seja possível mostrar vocabulários outros, ajudando a construir, assim, outras realidades. Se no início da nossa 
trajetória a descrição de espinhas, estrias e gorduras localizadas em corpos diversos poderia gerar constrangimento, ao final do projeto, estávamos certos de nossa decisão.

Mesmo com as tarefas de cada um da equipe perfeitamente delimitadas, a maioria das decisões finais eram tomadas em conjunto. Cada filme nos propunha um novo desafio e, nesse sentido, o fato da equipe ser multidisciplinar e composta por pessoas acima dos 35 anos nos ajudou a todos. Um exemplo disso foi a rotina criada para a confecção do produto.

Após a escrita do roteiro e a conversa entre a roteirista e o consultor, é chegada a hora da gravação em estúdio. Antes de cada gravação, uma chamada coletiva é feita para que todos da equipe acompanhem e opinem sobre timbre, interpretação entre outras coisas. Com a gravação finalizada e o áudio mixado ao som original, o filme é enviado para a produtora, a roteirista (que nesse caso também é a narradora) e o consultor. Após uma conversa, se necessário, voltamos ao estúdio para correções finais.

A parceria e acompanhamento dos profissionais do início ao final da confecção do produto provou ser a dinâmica mais interessante para esse grupo.

\section{Considerações finais}

O relato aqui feito busca refletir sobre o processo inédito da realização de acessibilidade para filmes pornográficos de produção brasileira. Longe de propor um formato fechado, receita de bolo ou solução, compartilhamos inquietações só possíveis de existir por meio das práticas que aconteceram durante o período de execução do projeto. Ao observar as questões que apareciam, confirmamos o quão viva e integrada à sociedade a audiodescrição é, mesmo sendo ainda desconhecida do público em geral, apesar desse recurso ter surgido em meados dos anos 1970 nos Estados Unidos e ser usado, no Brasil, a partir do ano de 2003 no âmbito profissional. Desde então, a audiodescrição vem sendo disponibilizada nos mais diversos segmentos, tais como imagens estáticas, dinâmicas, eventos ao vivo e também em imagens táteis. Esse recurso de acessibilidade comunicacional que converte informações do signo visual para o signo verbal é conceituado como uma tradução intersemiótica.

Com o início do projeto e a disponibilização dos filmes acessíveis por meio de um canal por assinatura, usuários da audiodescrição passaram a ter acesso aos conteúdos de forma plena e equânime com os demais da sociedade. Com a confecção dos roteiros, fícou impossível não se atentar para temas como machismo, feminismo, colorismo, preconceito, 
autonomia e, é claro, acessibilidade. Assim, os consumidores passam a receber o conteúdo e desenvolver suas próprias reflexões.

A pesquisa prévia empreendida sobre o tema, com retorno positivo de grupo heterogêneo de consumidores regulares de conteúdos pornográficos com deficiência visual, somada ao trabalho em equipe dissiparam as inseguranças que cercaram o início do trabalho, inovador tanto no aspecto de produção como no aspecto de tradução audiovisual. Assim, a partir da realização desse projeto de acessibilidade audiovisual para filmes pornográficos vislumbram-se novas possibilidades e pesquisas na área, necessárias para que, cada vez mais, os produtos audiovisuais pornográficos acessíveis ampliem sua qualidade de modo a atender as especificidades do público consumidor.

\section{REFERÊNCIAS BIBLIOGRÁFICAS}

BRANDÃO, Felipe. Conheça os canais pornográficos disponíveis na TV brasileira. Observatório da TV, 2020. Disponível em:

$<$ https://observatoriodatv.uol.com.br/noticias/conheca-os-canais-pornograficos-disponiveisna-tv-brasileira>. Acesso em: 5 mar. 2021.

BRASIL. Decreto No 5.296, de 2 de dezembro de 2004. Disponível em: $<$ http://www.planalto.gov.br/ccivil 03/ ato20042006/2004/decreto/d5296.htm\#: :text=-Nas\%20edifica\%C3\%A7\%C3\%B5es\%20de\%20uso\% 20p\%C3\%BAblico,Art>. Acesso em: 4 maio 2021.

BRASIL. Lei No 10.098, de 19 de dezembro de 2000. Estabelece normas gerais e critérios básicos para a promoção da acessibilidade das pessoas portadoras de deficiência ou com mobilidade reduzida, e dá outras providências. Disponível em:

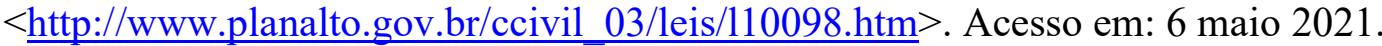

BRASIL. Lei N ${ }^{o}$ 13.146, de 6 de julho de 2015. Institui a Lei Brasileira de Inclusão da Pessoa com Deficiência (Estatuto da Pessoa com Deficiência). Disponível em: $<$ http://www.planalto.gov.br/CCIVIL 03/ Ato2015-2018/2015/Lei/L13146.htm>. Acesso em: 4 fev. 2021.

FRANCO, Eliana Paes Cardoso; SILVA, Manoela Cristina Correia Carvalho da. Audiodescrição: breve passeio histórico. In: MOTTA, Lívia Maria Vilela Melo ROMEU Fo, Paulo. (Orgs.) Audiodescrição: transformando imagens em palavras. São Paulo: Secretaria de Estado dos Direitos da Pessoa com Deficiência, 2010.

LIMA, Francisco J.; LIMA, Rosângela A. F.; GUEDES, Lívia C. Em Defesa da Áudiodescrição: contribuições da Convenção sobre os Direitos da Pessoa com Deficiência. Revista Brasileira de Tradução Visual, v.1, n.1, 2009. Disponível em: $<$ http://www.associadosdainclusao.com.br/enades2016/sites/all/themes/berry/documentos/02- 
em-defesa-da-audio-descricao-contribuicoes-da-convencao-sobre-os-direitos-da-pessoa-comdeficiencia.pdf $>$. Acesso em: 3 jan. 2021.

LIMA, Francisco J.; TAVARES, Fabiana S. S. Subsídios para a construção de um código de conduta profissional do áudio-descritor. Revista Brasileira de Tradução Visual, v.5, n.5, 2010. Disponível em: $<$ https://adww.online/subsidios-para-a-construcao-de-um-codigo-deconduta-profissional-do-audio-descritor/>. Acesso em: 20 jan. 2021.

LIMA, Francisco J.; GUEDES, L. C. e GUEDES, M. C. Áudio-descrição: orientações para uma prática sem barreiras atitudinais. Revista Brasileira de Tradução Visual, v.2, n.2, 2010. Disponível em: $<$ https://adww.online/audio-descricao-orientacoes-para-uma-pratica-sembarreiras-atitudinais/>. Acesso em: 3 jan. 2021.

MONTEIRO, Felipe Vieira. Análise de lexias "tabus" na audiodescrição de imagens estáticas de sexo explícito no filme "A história da eternidade". UECE, 2018. 54 f. TCC Especialização em Tradução audiovisual acessível: audiodescrição - Centro de Humanidades, Universidade Estadual do Ceará, Fortaleza, 2018. Disponível em:

$<$ https://siduece.uece.br/siduece/trabalhoAcademicoPublico.jsf?id=85501 $>$. Acesso em: 12 set. 2020.

MURARO, Cauê. Estudo divulgado pelo canal Sexy Hot mostra detalhes do consumo pornô no Brasil e preferências do público. Material lista cinco perfis de quem assiste a filmes pornográficos. Quantas pesquisas e estudos de mercado. 17 de maio de 2018. Disponível em: $<$ https://quantas.com.br/22-milhoes-de-brasileiros-assumem-consumir-pornografia-e-76sao-homens-diz-pesquisa/>. Acesso em: 10 jan. 2021.

NAVARRO, M. Hernandez; LOPEZ, Evelio M. Accesibilidad de la cultura visual: límites y perspectivas. Integración - Revista sobre ceguera y deficiencia visual, n. 40, p. 21-28, 2002.

PROGRAMAÇÃO Venus (Canal 284 Claro TV). Claro.com.br, 2021. Disponível em: $<$ https://www.claro.com.br/tv-por-assinatura/programacao/grade/programa/venus/528>. Acesso em: 5 mar. 2021.

SACCHITIELLO, Bárbara. Os planos da primeira mulher à frente do Grupo Playboy. Meio \& Mensagem, ed. 7 de agosto de 2020. Disponível em: https://www.meioemensagem.com.br/home/midia/2020/08/07/os-planos-da-primeira-mulhera-frente-do-grupo-playboy.html Acesso em: 8 maio 2021.

SEXY Hot, prazer explícito. Canais Globosat, 2021. Disponível em:

$<$ http://canaisglobosat.globo.com/marca/sexy-hot/\#title>. Acesso em: 5 mar. 2021.

SEXTREME Sexo sem Limites! Canais Globosat, 2021. Disponível em:

$<$ http://canaisglobosat.globo.com/marca/sextreme/\#title>. Acesso em: 5 mar. 2021.

SNYDER, Joel (Ed.). Diretrizes para a áudio-descrição e práticas basilares. American Council of the Blind: 2010. 
SNYDER, Joel. Áudio-descrição: uma ajuda para a literacia. Trad. Paulo Vieira. Revista Brasileira de Tradução Visual, v.6, n.6, 2011. Disponível em: <https://adww.online/audiodescricao-uma-ajuda-para-a-literacia/>. Acesso em: 20 fev. 2021.

TAVARES, Fabiana S. S. et. al. Reflexões sobre o pilar da áudio-descrição: "descreva o que você vê". Revista Brasileira de Tradução Visual (RBTV), v.4, n.4, 2010. Disponível em: $<$ https://adww.online/reflexoes-sobre-o-pilar-da-audio-descricao-descreva-o-que-voce-ve/>. Acesso em: 10 jan. 2021.

VIEIRA, P.; LIMA, F. J. A teoria na prática: áudio-descrição, uma inovação no material didático. Revista Brasileira de Tradução Visual, v. 2, n. 2, 2010. Disponível em:

$<$ https://adww.online/teoria-na-pratica-audio-descricao-uma-inovacao-no-material-didatico/>. Acesso em: 4 nov. 2020. 